\title{
Potensi Ekstrak Etanol Biji Alpukat (Persea americana Mill.) sebagai Tabir Surya
}

\section{Potential of Avocado Seed (Persea americana Mill.) Ethanol Extract as Sunscreen}

\author{
Asriani Suhaenah*, Harti Widiastuti, Muslimin Arafat \\ ${ }^{1}$ Jurusan Ilmu Farmasi Fakultas Farmasi Universitas Muslim Indonesia Makassar, \\ Jl Urip Sumoharjo Km.5, Panaikang, Kec.Panakukang, Kota Makassar, Sulawesi Selatan \\ Kontak*: asriani.suhaenah@umi.ac.id
}

\begin{abstract}
ABSTRAK
Telah dilakukan penelitian potensi ekstrak etanol biji alpukat sebagai tabir surya. Tujuan dari penelitian ini untuk menentukan nilai Sun Protection Factor (SPF) ekstrak etanol biji alpukat (Persea americana Mill.). Simplisia biji diekstraksi dengan metode maserasi menggunakan larutan penyari etanol $96 \%$, kemudian dibuat larutan sampel dengan seri konsentrasi 200, 400, 600, 800 dan 1000 ppm. Selanjutnya larutan sampel diukur absorbansinya panjang gelombang 290-320 nm dengan interval $5 \mathrm{~nm}$. Hasil penelitian menunjukkan ekstrak etanol biji alpukat $1000 \mathrm{ppm}$ memiliki nilai SPF tertinggi yaitu 8,02, yang terkategori proteksi maksimal.
\end{abstract}

Kata Kunci : Ekstrak etanol biji alpukat, Tabir Surya, Sun Protection Factor (SPF)

\begin{abstract}
The potential of the avocado seed ethanol extract as a sunscreen has been conducted. The purpose of this study was to determine the value of Sun Protection Factor (SPF) of avocado seed ethanol extract (Persea americana Mill.). Seeds simplisia were extracted by maceration method using $96 \%$ ethanol extraction solution, then the sample solution was made into series concentration which are 200, 400,600, 800 and 1000 ppm. Then the absorbance of the sample is measured at 290-320 nm with $5 \mathrm{~nm}$ intervals. The results showed avocado seeds ethanol extract 1000 ppm had the highest SPF value which is 8.02, which was categorized as maximum protection.
\end{abstract}

Keywords: Avocado Seed Ethanol Extract, Sunscreen, Sun Protection Factor (SPF)

\section{PENDAHULUAN}

Indonesia merupakan negara yang beriklim tropis, yang memperoleh sinar matahari lebih banyak yang dapat menyebabkan kerusakan kulit akibat dari pancaran sinar ultraviolet. Efek yang ditimbulkan dari paparan sinar matahari dapat menyebabkan eritema dan sunburn (kulit terbakar), pigmentasi dan fotosensitivitas, dengan efek jangka panjang berupa penuaan dini dan kerusakan kulit. Efek-efek ini tergantung pada kekuatan intensitas matahari, frekuensi penyinaran, luas permukaan kulit yang terpapar sinar matahari dan kepekaan masing-masing individu terhadap paparan sinar matahari (Susanti, Dachriyanus, \& Putra, 2012). Kulit merupakan bagian tubuh terluar yang melapisi organ tubuh dan melapisi organ tubuh yang berkontak langsung dengan lingkungan luar sehingga butuh perlindungan.

Tabir surya merupakan sediaan kosmetik yang dirancang untuk mengurangi efek yang 
berbahaya dari terpaparnya kulit oleh sinar ultraviolet. Fungsi tabir surya adalah untuk melindungi kulit dari radiasi ultra-violet dalam sinar matahari yang dapat menimbulkan berbagai kerusakan pada kulit (Sami, Nur, \& Martini, 2015). Sun Protection Factor (SPF) merupakan indikator universal yang menjelaskan efektifitas produk atau zat yang bersifat $U V$ protector. Semakin besar nilai SPF dari suatu produk atau zat aktif tabir surya maka semakin efektif untuk melindungi kulit dari pengaruh buruk sinar UV (Susanti, Dachriyanus, \& Putra, 2012; Rusita \& Indrianto, 2017).

Biji alpukat kaya akan kandungan senyawa kimia. Analisis fitokimia mengungkapkan adanya flavonoid, antosianin, tanin terkondensasi, alkaloid dan triterpen dalam ekstrak metanol. Sterol dan triterpen juga terdeteksi dalam ekstrak heksana (LeiteI, et al., 2009). Biji alpukat juga dilaporkan kaya senyawa fenolik (Dabas, Shegog, Ziegler, \& Lambert, 2013). Kandungan senyawa flavonoid dalam biji alpukat adalah 1,90 mg dalam $100 \mathrm{~g}$ biji alpukat (Arukwe, et al., 2012). Senyawa kimia ini memainkan peran penting dalam efek kesehatan, termasuk sebagai tabir surya. Contoh umum tabir surya kimia termasuk oktalat dan avobenzone. Tabir surya kimia menyerap sinar UV dan mengubahnya menjadi energi panas yang kemudian dilepaskan dari kulit. Tabir surya kimia menghasilkan estetika yang lebih baik saat digunakan sehingga lebih diterima secara luas, walaupun mengandung potensi penyerapan sistemik sehingga sensitivitas dan efek yang tidak diinginkan lebih umum terjadi pada kelompok tabir surya ini (Geoffrey, Mwangi, \& Maru, 2019). Tabir surya dari bahan alam diharapkan dapat menjadi alternatif dengan efek merugikan yang kecil. Berdasarkan potensi tersebut di atas, maka dilakukan penelitian tentang potensi ekstrak etanol biji alpukat sebagai tabir surya. Penelitian ini menggunakan limbah biji alpukat sebagai sampel.

\section{METODE PENELITIAN}

\section{Bahan dan Alat}

Alat yang digunakan adalah alat-alat gelas, cawan porselin, mikropipet (Joan $\left.1 \mathrm{lab}^{\circledR}\right)$, seperangkat alat maserasi, seperangkat alat rotavapor (Ika $\mathrm{RV}^{\circledR} \quad 10$ digital), dan spektrofotometer UV-Visible (Thermo genesys $10 \mathrm{~S}^{\circledR}$ ). Bahan yang digunakan adalah etanol 96\% dan biji alpukat (Persea Americana Mill.).

\section{Ekstraksi sampel}

Biji alpukat disiapkan menjadi simplisia sebelum diekstraksi. Sampel alpukat dibelah lalu dipisahkan biji dari dagingnya. Kemudian biji dibersihkan dan dicuci dengan air mengalir. Biji alpukat dirajang untuk mempermudah proses pengeringan dan penggilingan. Biji alpukat dikeringkan dengan cara dijemur tanpa sinar matahari atau diangin-anginkan, kemudian dibuat serbuk simplisia dengan cara dihaluskan menggunakan blender dan diayak. 
Simplisia biji alpukat diekstraksi dengan metode maserasi. Simplisia biji alpukat sebanyak $500 \mathrm{~g}$ dimasukkan ke toples kaca lalu diisi dengan $700 \mathrm{ml}$ etanol 96\% hingga sampel terendam. Maserasi dilakukan selama 3 x 24 jam. Residu yang diperoleh diekstraksi kembali dengan $500 \mathrm{ml}$ etanol 96\%. Filtrat dari ekstraksi pertama dan kedua digabung. Selanjutnya pelarut diuapkan menggunakan rotary vaccum evaporator hingga diperoleh ekstrak kental (Abubakar, Aisyah, \& Baharuddin, 2014)

\section{Penentuan nilai SPF}

Ekstrak biji alpukat dibuat menjadi larutan sampel dengan konsentrasi 200, 400, 600, 800 dan 1000 ppm dalam pelarut etanol 96\% dari larutan stok 1000 ppm. Absorbansi dari setiap larutan sampel diukur pada daerah panjang gelombang 290-320 nm dengan interval $5 \mathrm{~nm}$ dengan menggunakan spektrofotometer UVVis. Etanol 96\% digunakan sebagai blangko (Ajwad, 2016).

Perhitungan nilai Sun Protection Factor (SPF) menggunakan persamaan Mansur (Mishra A.K.,Mishra A.,Chattopadhyay P.,

Tabel 1. Nilai hasil kali Erythemal Effect Spectrum (EE) dengan Intensity Spectrum (I) (Sayre, R.M., Agin, P.P.,Levee, G.J.,Marlowe, E.,, 1979)

\begin{tabular}{cl}
\hline Panjang gelombang $(\mathrm{nm})$ & EE x I \\
\hline 290 & 0,015 \\
295 & 0,0817 \\
300 & 0,2874 \\
305 & 0,3278 \\
310 & 0,1864 \\
315 & 0,839 \\
320 & 0,018 \\
\hline
\end{tabular}

2012) yaitu:

$$
\mathrm{SPF}=C F \sum_{290}^{320} \mathrm{EE}(\lambda) \times \mathrm{I}(\lambda) \times \operatorname{Abs}(\lambda)
$$

dimana: $\mathrm{EE}=$ Spektrum efek eritema, $\mathrm{I}=$ Intensitas Spektrum Sinar, Abs = Absorbansi sampel, $\mathrm{CF}=$ Faktor Koreksi (sebesar 10). Nilai EE X I adalah konstan dan ditunjukkan pada tabel 1 .

\section{HASIL DAN PEMBAHASAN}

Tabir surya digunakan untuk melindungi kulit dari radiasi UV yang berbahaya dari sinar matahari (Mbanga, et al., 2014). Sinar UV berada pada kisaran panjang gelombang 200-400 nm. Spektrum UV terbagi menjadi tiga kelompok berdasarkan panjang gelombang. Yaitu UV C (200-290 nm), UV B (290-320 nm) dan UV A (320-400 nm). Tidak seluruh radiasi sinar UV dari sinar matahari dapat mencapai permukaan bumi. Sinar UV C yang memiliki energi terbesar tidak dapat mencapai permukaan bumi karena mengalami penyerapan di lapisan ozon (COLIPA, 2006). Energi dari radiasi sinar ultraviolet yang mencapai permukaan bumi dapat menyebabkan terbakarnya kulit. Diantara tandanya adalah kemerahan pada kulit (eritema), rasa sakit, kulit melepuh dan terjadinya pengelupasan kulit. UV B merusak kulit dibandingkan dengan UV A sebab energinya yang lebih tinggi (Mulyani, Putri, \& Wahidatullail, 2015)

Nilai SPF merupakan nilai daya tahan tabir surya. Daya tahan tabir surya dengan mengalikan nilai SPF dengan 10. Tabir surya 
Tabel 2. Absorbansi sampel

\begin{tabular}{cccccc}
\hline Panjang Gelombang & \multicolumn{5}{c}{ Konsentrasi (ppm) } \\
\cline { 2 - 6 }$(\mathrm{nm})$ & 200 & 400 & 600 & 800 & 1000 \\
\hline 290 & 0,510 & 1,087 & 1,505 & 2,073 & 2,433 \\
295 & 0,252 & 0,558 & 0,724 & 1,043 & 1,201 \\
300 & 0,171 & 0,393 & 0,481 & 0,718 & 0,816 \\
305 & 0,153 & 0,355 & 0,432 & 0,647 & 0,732 \\
310 & 0,145 & 0,338 & 0,411 & 0,618 & 0,697 \\
315 & 0,137 & 0,322 & 0,392 & 0,590 & 0,662 \\
320 & 0,130 & 0,306 & 0,374 & 0,564 & 0,628 \\
\hline
\end{tabular}

Tabel 3. Hasil Perkalian Nilai EE X I dengan Absorban Sampel

\begin{tabular}{cccccc}
\hline Panjang Gelombang & \multicolumn{5}{c}{ Konsentrasi $(\mathrm{ppm})$} \\
\cline { 2 - 6 }$(\mathrm{nm})$ & 200 & 400 & 600 & 800 & 1000 \\
\hline 290 & 0,007 & 0,016 & 0,022 & 0,031 & 0,036 \\
295 & 0,020 & 0,045 & 0,059 & 0,085 & 0,098 \\
300 & 0,049 & 0,112 & 0,138 & 0,206 & 0,234 \\
305 & 0,050 & 0,116 & 0,141 & 0,212 & 0,239 \\
310 & 0,027 & 0,063 & 0,076 & 0,115 & 0,129 \\
315 & 0,011 & 0,027 & 0,032 & 0,049 & 0,055 \\
320 & 0,002 & 0,005 & 0,006 & 0,010 & 0,011 \\
\hline Total & 0,166 & 0,384 & 0,474 & 0,708 & 0,802 \\
\hline
\end{tabular}

dengan SPF 15 berarti akan melindungi kulit selama 150 menit dari paparan sinar ultraviolet sebelum kulit menjadi terbakar dan merah. Tanpa tabir surya, kulit yang terpapar sinar matahari langsung akan bertahan selama 10 menit sebelum kulit menjadi terbakar dan merah (Anton, 2007). Nilai SPF dapat dihitung dari kurva absorbansi tabir surya.

Absorbansi larutan sampel diukur pada panjang gelombang 290-320 nm yang merupakan panjang gelombang sinar UV-B yang berada pada daerah eritmogenik yang dapat menimbulkan sengatan surya (Pramiastuti, 2019). Nilai absorbansi sampel meningkat setiap kenaikan konsentrasi, kemudian dihitung nilai SPF menggunakan persamaan Mansur. Nilai Absorbansi dari sampel dapat diliat pada tabel 2.
Hasil perhitungan nilai Sun Protection Factor (SPF) ekstrak etanol biji alpukat dengan metode spektrofotometri UV-Vis yang dihitung menggunakan persamaan Mansur dapat dilihat pada lampiran tabel 3. Efektivitas tabir surya berdasarkan hasil perhitungan dari sampel ekstrak etanol biji alpukat paling besar pada konsentrasi 1000 ppm. Nilai SPF pada konsentrasi tersebut adalah 8,02. Dengan nilai tersebut, potensinya termasuk dalam proteksi maksimal. Nilai SPF diklasifikasikan sebagai potensi proteksi minimal (1-4), proteksi sedang (4-6), proteksi ekstra (6-8), proteksi maksimal (8-15), dan proteksi ultra (>15). (Lintang \& Charisma, 2017).

Berdasarkan data yang diperoleh dapat dinyatakan bahwa semakin tinggi konsentrasi 
Tabel 4. Nilai SPF Sampel Ekstrak Etanol Biji Alpukat (Persea americana Mill.) Pada Beberapa Konsentrasi

\begin{tabular}{ccc}
\hline $\begin{array}{c}\text { Konsentrasi } \\
\text { sampel } \\
(\mathrm{ppm})\end{array}$ & Nilai SPF & Kategori SPF \\
\hline $200 \mathrm{ppm}$ & 1,66 & Minimal \\
$400 \mathrm{ppm}$ & 3,84 & Minimal \\
$600 \mathrm{ppm}$ & 4,74 & Sedang \\
$800 \mathrm{ppm}$ & 7,06 & Ekstra \\
$1000 \mathrm{ppm}$ & 8,02 & Maksimal \\
\hline
\end{tabular}

yang digunakan maka nilai SPF yang diperoleh juga akan semakin tinggi. Banyaknya jumlah senyawa metabolit sekunder seperti senyawa flavonoid, saponin, tanin, alkaloid, fenol, dan steroid berperan yang semakin meningkat juga menyebabkan jumlah sinar yang diabsorbansi juga meningkat. Arukwe dkk (2012) memperoleh bahwa ekstrak etanol biji alpukat mengandung flavonoid berkisar $1,90 \mathrm{mg}$, saponin 19,21 mg, tanin 0,24 mg, alkaloid 0,72 mg, fenol 6,41 mg, dan steroid 0,09 mg dihitung terhadap 100 gram biji. Jenny Pontoan (2016) menyatakan bahwa senyawa aktif dari ekstrak etanol daun alpukat yang berpotensi sebagai tabir surya adalah flavonoid (Jenny, 2016). Senyawa flavonoid dalam tabir surya bekerja dengan cara menyerap sinar yang masuk ke kulit sehingga dapat mengurangi kerusakan kulit yang disebabkan sinar ultraviolet (Wolf, R., D.Wolf, P. Morganti, \& V. Ruocco.,, 2001).

Selain bekerja mengabsorbsi sinar uv, senyawa antioksidan dalam biji alpukat juga mendukung aktivitas tabir surya melalui mekanisme sekunder, yaitu dengan perbaikan jaringan. Penambahan antioksidan dalam tabir surya dapat memberikan perlindungan tambahan untuk menetralisir spesies oksigen reaktif dari sumber endogen dan eksogen (Lucy Chen, Judy Y. Hu, \& Steven Q. Wang, 2012). Antioksidan digunakan untuk meredam dampak negatif dari berbagai penyakit yang ditimbulkan oleh radiasi sinar UV (Sutriningsih \& Astuti, 2016). Mustopa (2015) menunjukkan bahwa ekstrak kental biji buah alpukat memiliki potensi antioksidan $\left(\mathrm{IC}_{50}\right)$ 44,58 ppm dihitung terhadap DPPH. Nilai ini menjelaskan bahwa antioksidan biji alpukat sangat kuat. Senyawa flavonoid dan fenolik berperan paling bersadapat mendukung kerja tabir surya berperan paling besar berfungsi sebagai antioksidan yang dapat menghambat kerja radikal bebas (Hanani, E., A. Mun'im, \& R. Sekarini, 2005).

\section{KESIMPULAN}

Berdasarkan hasil penelitian dapat disimpulkan bahawa ekstrak etanol biji alpukat memiliki nilai SPF tertinggi pada konsentarsi 1000 ppm dengan nilai SPF 8,02 yang tergolong kategori proteksi maksimal.

\section{DAFTAR PUSTAKA}

Abubakar, A. N., Aisyah, \& Baharuddin, M. (2014). Isolasi Senyawa Aktif Ekstrak Etanol Biji Alpukat (Persea americana) dan Uji Toksisitas terhadap Artemia Salina Leach. Al-Kimia, 2(1), 25-32.

Ajwad, M. N. (2016). Uji Potensi Tabir Surya dan Nilai Sun Protecting Factor (SPF) Ekstrak Etanol Daun Pedang-Pedang (Sansevieria trifasciata Prain) secara in vitro. Makassar: Uin Alauddin Makassar. 
Anton, A. (2007). The Miracle Of Jilbab Hikmah Cantik dan Sehat Secara Ilmiah Dibalik Syariat Jilbab. Share Digital Publishing, 56-57.

Arukwe, U., Amadi, B., Duru, M. K., Agomuo, E., Adindu, E. A., Odika, P., . . . Anudike, J. (2012). Chemical Composition of Persea americana Leaf, Fruit And Seed. IJJRAS. 11, 346-348.

COLIPA. (2006). COLIPA Guidlines :International Sun Protection Factor Test Method.

Dabas, D., Shegog, R., Ziegler, G., \& Lambert, J. (2013). Avocado (Persea americana) seed as a source of bioactive phytochemicals. Curr Pharm Des, 19(34), 6133-6140.

Geoffrey, K., Mwangi, A. N., \& Maru, S. M. (2019). Sunscreen products: Rationale for use, formulation development and regulatory considerations. Saudi Pharmaceutical Journal, 27(7), 10091018.

Hanani, E., A. Mun'im, \& R. Sekarini. (2005). Identifikasi Senyawa Antioksidan dalam Spons Callyspongia sp dari Kepulauan Seribu. Majalah Ilmu Kefarmasian 2(3), 127-133.

Jenny, P. (2016). Uji Aktivitas Antioksidan Dan Tabir Surya Dari Ekstrak Daun Alpukat (Persea americana Mill.). Indonesia Natural Research Pharmaceutical Journal Vo.1 No.1, 55-66.

LeiteI, J. J., BritoI, É. H., CordeiroI, R. A., BrilhanteI, R. S., SidrimI, J. J., Bertini, L. M., . . . Rocha, M. F. (2009). Chemical composition, toxicity and larvicidal and antifungal activities of Persea americana (avocado) seed extracts. Revista da Sociedade Brasileira de Medicina Tropical, 42(2).

Lintang, S., \& Charisma. (2017). Daya Tabir Surya Dan Antioksidan Formula Krim Ekstrak Rimpang Kencur (Kaempferia galanga L) Dan Rimpang Temu Kunci (Boesenbergia pandurata(Roxb)Schlecht. Purwokerto: Repository Universitas Muhammadiyah Purwokerto.

Lucy Chen, B., Judy Y. Hu, M., \& Steven Q. Wang, M. (2012). The role of antioxidants in photoprotection: A critical review.
Journal of the American Academy of Dermatology, 67(5), 1013-1024.

Mbanga, L., Mulenga, M., Mpiana, P., Bokolo, K., Mumbwa, M., \& Mvingu, K. (2014). Determination of Sun Protection Factor (SPF) of Some Body Creams and Lotions Marketed in Kinshasa by Ultraviolet Spectrophotometry. International Journal of Advanced Research in Chemical Science, 1(8), 7-13.

Mishra A.K.,Mishra A.,Chattopadhyay P. (2012). Assessment Of In Vitro Sun Protection Factor (SPF) Number Of Calendula officinalis L. (Asteraceae) essential Oil Formulation. J. Young Pharmacists, 17-21.

Mulyani, Putri, P., \& Wahidatullail, N. (2015). Penentuan Nilai SPF (Sun Protecting Factor) Ekstrak N-Heksan Dari Rice Bran (Oryza sativa) Secara In Vitro Dengan Metode Spektrofotometri UV-Vis. Natural Science: Journal of Science and Technology, 4(1), 89-95.

Mustopa, L. H. (2015). Uji Potensi Antioksidan Ekstrak Etanol Biji Alpukat(Persea americana Mill) dan Pengembangan Formulasi Krim Antioksidannya. Bandung: Kementrian Kesehatan RI Poltekes Bandung.

Pramiastuti, O. (2019). Penentuan Nilai SPF(Sun Protecting Factor) Ekstrak Daun Kecombrang (Etlingera elatior) Secara In Vitro Menggunakan Metode Spektrofotometri. Jurnal Para Pemikir Vol 8(1), 14-18.

Rusita, Y., \& Indrianto, A. (2017). Aktivitas Tabir Surya dengan Nilai Sun Protection Factor (SPF) Sediaan Lotion KOmbinasi Ekstrak Kayu Manis dan Ekstrak Kulit Delima pada Paparan Sinar Matahari dan Ruang Tertutup. Jurnal Kebidanan dan Kesehatan Tradisional, Vol. 2, No. 1,, 3843.

Sami, F., Nur, S., \& Martini, M. (2015). Uji Aktivitas Tabir Surya pada Beberapa Spesies dari Famili Zingeberaceace dengan Metode Spektrofptpmetri. As-Syifaa Vol 07(02), 164-173.

Sayre, R.M., Agin, P.P.,Levee, G.J.,Marlowe, E.,. (1979). Comparison Of In Vivo and in Vitro Testing of Sunscreening Formulas. Photochem, photobiol 29, 559-566. 
Susanti, M., Dachriyanus, \& Putra, D. (2012). Aktivitas Perlindungan Sinar UV Kulit Buah Garcinia mangostana Linn Secara In Vitro. Pharmacon Vol.13 No.2, 61.

Sutriningsih, \& Astuti, I. (2016). Uji Antioksidan dan Formilasi Sedian Masker Pell-Off dari Ekstrak Biji Alpukat (Persea americana Mill.) dengan Perbedaan Kosentrasi PVA (Polfifenol alcohol). Indonesia Natural Research pharmaceutical journal, 68.

Wolf, R., D.Wolf, P. Morganti, \& V. Ruocco.,. (2001). Spectrophotometric Analysis And Modeling Of Sunscreens. Journal of Chemical Education. Washington., 99-102. 